\title{
Visibilitas Website UIN Syarif Hidayatullah Jakarta dalam Pemeringkatan Webometrics
}

\author{
${ }^{1}$ Parhan Hidayat, ${ }^{2}$ Muhammad Azwar \\ ${ }^{12}$ Universitas Islam Negeri Syarif Hidayatullah Jakarta \\ E-mail: parhan.hidayat@uinjkt.ac.id \\ ${ }^{2}$ E-mail: muh.azwar@uinjkt.ac.id
}

\begin{abstract}
This article attempts to describe the efforts to increase the visibility of the website of UIN Syarif Hidayatullah Jakarta in webometrics ranking. Webometrics is a means to measure the progress of a university through its website. This article aims to find the right work steps in an effort to increase website visibility and also the birth of practical steps to lift webometrics rankings that can be used as guidelines by website managers at UIN Syarif Hidayatullah Jakarta. This research uses a qualitative approach with a descriptive type. The main data was obtained using Focus Group Discussion (FGD) techniques by presenting parties related to webometrics ranking, having knowledge of SEO practices, and having experience in web management. The findings indicate that there have been efforts to increase the quantity and quality of content with the establishment of the publication and documentation division. There are still various obstacles to be faced, such as content management that does not meet SEO principles, several pages and subdomains that are not maintained, are damaged, and even lost, causing bad backlinks. It is necessary to build a website that uses the multisite method which is very effective and efficient in integrating various website needs at UIN Jakarta. The need for various efforts to overcome these obstacles, such as the need for effective communication between web development teams, the need for SEO-friendly content writing training, and the importance of SOPs in optimizing web performance and getting maximum webometrics ranking.
\end{abstract}

Keywords: Webometrics Ranking; Visibility; UIN Syarif Hidayatullah Jakarta Website

\begin{abstract}
Abstrak
Artikel ini berupaya mendeskripsikan upaya dalam meningkatkan visibilitas website UIN Syarif Hidayatullah Jakarta dalam pemeringkatan webometrics. Webometrics merupakan salah satu sarana untuk dapat mengukur peningkatan kemajuan suatu perguruan tinggi melalui website yang dimilikinya. Artikel ini bertujuan untuk menemukan langkah kerja yang tepat
\end{abstract}

Tik Ilmeu : Jurnal Ilmu Perpustakaan dan Informasi IAIN Curup | p-issn: 2580-3654; e-issn:2580-3662

DOI: $10.29240 /$ tik.v5i1.2056 
dalam upaya meningkatkan visibilitas website dan juga lahirnya langkahlangkah praktis untuk mengangkat peringkat webometrics yang dapat digunakan sebagai pedoman oleh pengelola website di UIN Syarif Hidayatullah Jakarta. Penelitian ini menggunakan pendekatan kualitatif dengan jenis deskriptif. Data utama diperoleh dengan menggunakan teknik Focus Group Discussion (FGD) dengan menghadirkan pihak yang berkaitan dengan perangkingan webometrics, memiliki pengetahuan tentang praktik SEO, dan berpengalaman dalam pengelolaan web. Hasil temuan menunjukkan bahwa sudah ada upaya untuk meningkatkan kuantitas dan kualitas konten dengan dibentuknya divisi Publikasi dan Dokumentasi. Masih terdapat berbagai kendala yang dihadapi, seperti manajemen konten yang belum memenuhi kaidah SEO, beberapa page dan subdomain yang tidak terawat, rusak, bahkan hilang sehingga menimbulkan bad backlink. Perlunya dibangun website yang menggunakan metode multisite yang sangat efektif dan efisien dalam integrasi berbagai kebutuhan website di UIN Jakarta. Perlunya berbagai upaya untuk mengatasi kendala tersebut, seperti perlunya komunikasi yang efektif antar tim pengembangan web, perlunya pelatihan penulisan konten yang ramah SEO, dan pentingnya SOP dalam mengoptimalkan performa web dan mendapatkan perangkingan webomterics yang maksimal.

Kata Kunci: Pemeringkatan Webometrics; Visibility; Website UIN Syarif Hidayatullah Jakarta

\section{A. PENDAHULUAN}

Website sebuah perguruan tinggi dapat dianggap sebagai wakil perguruan tinggi di dunia maya. Keberadaan website bagi perguruan tinggi dapat berfungsi sebagai pemberi informasi penting kepada masyarakat tentang pelaksanaan tridharma perguruan tinggi yang terdiri dari proses pengajaran, pelaksaanan penelitian dan beragam pengabdian yang telah dilaksanakan. Melalui wesbite itulah, masyarakat dapat menemukan informasi yang diperlukan ketika akan meneruskan pendidikan ke perguruan tinggi.

Mengelola sebuah website, apalagi sebuah website perguruan tinggi besar, tentu saja bukan hal yang mudah. Banyak usaha yang harus dilakukan agar website dapat selalu siap diakses, dari mulai jaringan internet yang harus terus stabil sampai dengan bagaimana cara mengelola konten website agar selalu update dan menarik. Menyadari betapa sulit dan betapa pentingnya pengelolaan website ini, Webometrics kemudian lahir untuk melakukan perangkingan pada kinerja website perguruan tinggi. Dengan adanya 
perangkingan atau pemeringkatan ini, Webometrics berharap bahwa gambaran kinerja perguruan tinggi yang sebenarnya dapat ditangkap secara utuh melalui website yang dibuatnya. Webometrics bahkan memperkirakan, bahwa pada mulai tahun 2020 dan selanjutnya ini, website akan dijadikan alat utama oleh perguruan tinggi untuk menjalankan seluruh visi dan misi yang dijalankannya (Aguillo, 2015b).

Melalui metodologi pemeringkatan yang dirilis dalam website resminya, Webometric menyebutkan bahwa ada 4 indikator inti yang dijadikan panduan dalam menilai kinerja sebuah website. Empat indikator utama yag dijadikan standar itu adalah presence, visibility, transparency (opennesse), dan exellence atau scholar. Presence merupakan jumlah halaman web (webpage) dari domain dan seluruh subdomain website. Presence hanya mewakili $5 \%$ saja dari total keseluruhan nilai yang diberikan. Selanjutnya adalah visibility. Visibility dapat disebutkan sebagai jumlah keseluruhan jaringan eksternal yang memberikan backlink pada website perguruan tinggi. Visibility ini adalah penyumban skor penilaian tertinggi, yaitu 50\%. Indikator berikutnya adalah transparency. Transperancy ini merupakan data yang diperoleh dari Google Scholar. Webometrics lebih familiar menyebutnya sebagai Transparant Ranking. Skor transparant rangking ini adalah $10 \%$. Selanjutnya, Indikator terakhir adalah Exellence atau scholar, yaitu penilaian yang didasarkan pada berapa jumlah paper yang masuk dalam kategori $10 \%$ paper yang paling banyak dikutip di Scopus (Muntashir, 2012).

Webometrics sendiri adalah sebuah lembaga pemeringkatan yang dibentuk di negara matador, Spanyol. Pada awal berdirinya, Webometrics diprakarsai oleh Cybermatics Lab. Selajutnya, webometrics dikembangkan oleh sekelompok peneliti yang tergabung dalam organisasi penelitian yang bernama Consejo Superior de Investigaciones Cientifics (CSIC). Webometrics tidak hanya menyasar website perguruan tinggi untuk diteliti tetapi juga website-website lainnya. Selain pemeringkatan website perguruan tinggi, webometrics juga menganalisis website lembaga penelitian, pusat bisnis, repository dan juga website rumah sakit. Webometrics melakukan pemeringkatan secara global di seluruh negara termasuk website-website berbagai lembaga yang mereka miliki (Aguillo, 2015a).

Eksistensi webometrics ini dapat mengukur berbagai aktivitas dan visibilitas yang dapat dijadikan indikator yang tepat untuk meningkatkan prestise sebuah institusi kampus. Webometrics dapat diakses dengan sangat mudah dan terbuka untuk umum melalui halaman 
http://www.webometrics.info. Webometrics sudah mendapatkan pengakuan secara internasional termasuk di Indonesia (Supradono, 2010).

Analisis webometrics ini merupakan salah satu sarana yang sangat penting untuk mengukur secara kuantitatif aktifitas dan kinerja suatu web. Tabel berikut ini berisi informasi mengenai penggunaan sejumlah Search Engine Optimization atau biasa disingkat dengan SEO yang berisi variabel dan web tools yang yang digunakan untuk mengukur indikator (Maryam et al., 2010).

Tabel 1: Penggunaan SEO untuk Mengukur Indikator Pemringkatan Webometrics

\begin{tabular}{|c|c|c|}
\hline Variabel & Keterangan & $\begin{array}{c}\text { Web tools yang } \\
\text { digunakan }\end{array}$ \\
\hline Visibility / visibilitas & $\begin{array}{l}\text { Tautan eksternal yang } \\
\text { terhubung ke domain } \\
\text { web }\end{array}$ & $\begin{array}{l}\text { Kualitas link eksternal } \\
\text { yang berasal dari web } \\
\text { lain berdasarkan data } \\
\text { visibility menggunakan } \\
\text { informasi data dari } 2 \\
\text { search engine, } \\
\text { MajesticSEO dan } \\
\text { Ahrefs. }\end{array}$ \\
\hline $\begin{array}{l}\text { Presence / } \\
\text { ketersediaan }\end{array}$ & $\begin{array}{l}\text { Jumlah halaman web } \\
\text { dan halaman dinamis } \\
\text { yang dapat diindeks } \\
\text { oleh search engine, } \\
\text { seperti Google, yang } \\
\text { bukan berisi rich files. }\end{array}$ & $\begin{array}{l}\text { Search Engine Google } \\
\text { dan Bing }\end{array}$ \\
\hline $\begin{array}{l}\text { Openness / } \\
\text { keterbukaan }\end{array}$ & $\begin{array}{l}\text { Jumlah file dokumen } \\
\text { yang ada dengan } \\
\text { berbagai format seperti, } \\
\text { pdf, docs, ppt dan } \\
\text { format lainnya yang } \\
\text { dapat diakses secara } \\
\text { terbuka di dalam } \\
\text { domain website } \\
\text { kampus. }\end{array}$ & Google Scholar \\
\hline Excellence / & $\begin{array}{l}\text { Jumlah makalah, } \\
\text { seminar, karya } \\
\text { publikasi ilmiah yang } \\
\text { diterbitkan dalam jurnal } \\
\text { internasional yang } \\
\text { dipublikasikan oleh }\end{array}$ & $\begin{array}{l}\text { Google Scholar dan } \\
\text { Scimago Institution } \\
\text { Ranking. }\end{array}$ \\
\hline
\end{tabular}




\section{perguruan tinggi \\ tersebut terindeks di \\ Google Scholar dan di \\ Scimago Institution \\ Ranking.}

Penelitian tentang webometrics dalam ranah ilmu perpustakaan dan informasi, memang sudah cukup banyak yang dilakukan. Penulis kemudian berusaha mencari bagian mana yang belum banyak diteliti dalam penelitian webometrics. Bila bagian itu berhasil ditemukan maka penelitian akan memiliki nilai analisis yang beda (gap analisys) dengan penelitian serupa lainnya.

Beberapa penelitian tentang webometrics yang ditemukan penulis di antaranya adalah penelitian dengan judul "Peningkatan Rank Webometrics Menggunakan Metode Inbound dan Outbound Pada Perguruan Tinggi". Penelitian ini diterbitkan oleh jurnal ilmiah Sisfotenika, Volume 2, Tahun 2017 (Rahardja et al., 2017). Penelitian dilakukan untuk mencari cara dalam meningkatkan rangking webometrics perguruan tinggi Raharja, https://raharja.ac.id/. Penelitian dilakukan dengan memakai teknik mind mapping. Teknik mind mapping bertujuan agar informasi yang disampaikan menjadi lebih mudah untuk dimengerti. Teknik ini menghasilkan 10 level inbound. Kesepuluh level inbound tersebut adalah profile inbound, share inbound, comment inbound, post inbound, story inbound, link exchange inbound, static inbound, contribution inbound, wiki inbound, dan terakhir template inbound.

Selain dengan pendekatan inbound, penelitian ini juga menggunakan metode outbond dengan cara melakukan penyebarkan link dari seluruh subdomain website. Link tersebut disebarkan ke berbagai artikel, video dan bahkan sebagian ada yang disimpan dalam website partner. Pengelola website raharja.ac.id juga menampilkan dan menyediakan listing program yang di dalamnya tersimpan alamat website lembaga lain.

Penelitian ini menunjukan bahwa tehnik inbound dan outbond ternyata cukup berhasil berhasil menaikan peringkat Webometrics. Selama 4 bulan penelitian ini dilakukan, website raharja.ac.id yang pada awalnya berada di peringkat 303 di Januari 2016, naik cukup signifikan pada posisi 233 pada periode bulan Juli 2016. Metode inbound dan outbond ini dianggap berhasil mengangkat peringkat naik website raharja.ac.id naik 70 tingkat dari sebelumnya.

Penelitian tersebut di atas hampir memiliki tujuan yang sama dengan penelitian penulis yaitu untuk meningkatkan visibilitas website. Perbedaanya 
terletak pada metode penelitian yang diterapkan. Penelitian sebelumnya mencoba untuk lebih fokus pada pendekatan inbound dan outbound untuk membangun link (link building), sementara penelitian yang penulis lakukan berusaha mencari alternatif lain dalam upaya peningkatan visibilitas, tidak terlalu menggantungkan pada link building.

Peringkat website UIN Jakarta, uinjkt.ac.id, dalam pemeringkat webometrics menunjukan hasil yang tidak tetap (fluktuatif) dalam setiap periode pemeringkatannya. Peringkat tertinggi pernah diraih UIN Jakarta pada periode pemeringkatan bulan Juli 2015 dengan posisi ke 20 di tingkat nasional. Kemudian terakhir di periode Januari 2021 UIN Jakarta hanya berhasil menempati posisi ke 47 Nasional. Ini menunjukan bahwa website perguruan tinggi di seluruh Indonesia terus bergerak dinamis.

Menyadari bahwa indikator visibility merupakan bagian dari penilaian yang memiliki porsi paling besar yaitu 50\%, maka UIN Jakarta dirasa sangat perlu untuk melakukan langkah-langkah kreatif agar dapat meningkatkan skor pada indikator visibility di periode pemeringkatan ke depannya nanti. Langkah yang paling mungkin untuk dilakukan adalah dengan cara meningkatkan jumlah backlink dan referring domain ke website UIN Jakarta. Tetapi, perlu diketahui bahwa dalam ranah ilmu Search Engine Optimization atau SEO, backlink dan referring domain bukanlah sesuatu yang mudah untuk didapatkan. Untuk mendapatkan jumlah backlink yang banyak, website harus cukup populer di masyarakat secara umum maupun pengguna internet itu sendiri (netizen). Website populer adalah website yang memiliki jumlah kunjungan yang sangat tinggi. Hal ini biasanya website memiliki isi atau content web yang cukup menarik (Pribadi, 2010; Saputra et al., 2020).

Ketika penulis menggunakan perangkat SEO berbasis web yaitu https://ahrefs.com/, diperoleh sebuah data penting bahwa subdomain UIN Jakarta yang paling banyak menghasilkan backlink adalah http://repository.uinjkt.ac.id/dspace/. Subdomain ini memberikan backlink lebih dari 3 juta. Dengan berpedoman pada adanya subdomain yang potensial seperti ini, UIN Jakarta dapat mengetahui bagaimana caranya agar seluruh subdomain di bawah url https://www.uinjkt.ac.id/, dapat menghasilkan jumlah backlink yang berlimpah.

Latar belakang itulah yang kemudian menarik perhatian penulis untuk melakukan penelitian seputar bagaimana caranya meningkatkan visibilitas website UIN Syarif Hidayatullah Jakarta dalam pemeringkatan webometrics. Dengan berpijak pada latar belakang itu, maka fokus utama 
dalam tulisan ini adalah untuk menjawab beberapa pertanyaan penting. Pertama, bagaimana upaya pengembangan web UIN Syarif Hidayatullah Jakarta?. Kedua, langkah apa yang harus dilakukan agar seluruh isi atau content web di uinjkt.ac.id dapat terindeks oleh google?. Ketiga, bagaimana agar backlink uinjkt.ac.id dapat terus bertambah?. Keempat, Langkah apa yang paling tepat agar referring domain terhadap unjkt.ac.id terus meningkat?. Kelima, upaya apa yang harus dilakukan untuk menghadapi berbagai kendala dalam meningkatkan visibilitas uinjkt.ac.id?.

Pendekatan yang digunakan dalam Penelitian ini dilakukan adalah pendekatan kualitatif. Menurut Fraenkel dan Wallen (2014), penelitian kualitatif adalah penelitian yang berupaya mengetahui kualitas sebuah hubungan di antara berbagai elemen yang ada di lapangan, kegiatan-kegiatan yang ada, situasi dan kondisi yang berkembang atau sumber-sumber data tertentu. Perbedaan utama kualitatif dengan kuantitatif adalah kualitatif mencoba berfokus pada diperolehnya gambaran yang menyeluruh dari sebuah permasalahan yang ada.

Ada dua alat utama yang digunakan penulis dalam penelitian ini untuk memperoleh data yang diinginkan. Pertama adalah tool SEO berbasis website yaitu https://ahrefs.com/. Ahrefs merupakan website berbayar yang dapat digunakan untuk melakukan analisis SEO pada sebuah website. Kedua alat untuk mengumpulkan data adalah dengan menggunakan teknik Focus Group Discussion (FGD). FGD menurut Hollander (2004) adalah suatu metode yang digunakan dalam pendekatan kualitatif untuk memperoleh data atau informasi dengan cara interaksi sosial yang dilakukan oleh sekelompok individu, di mana dalam kelompok tersebut semua individu saling mempengaruhi satu sama lainnya. Dalam konteks penelitian ini, data-data yang diperoleh dari hasil analisis ahrefs.com ditunjukan kepada seluruh peserta FGD. Data-data itu kemudian didiskusikan bersama-sama. Dari hasil diskusi tersebut diperoleh berbagai persamaan pendapat. Namun pada sisi lain diperoleh juga beberapa pendapat yang berbeda. Hasil-hasil diskusi inilah yang pada nantinya akan dijadikan sumber data utama untuk melakukan langkah yang tepat dalam meningkatkan visibilitas uinjkt.ac.id. Seluruh peserta FGD memiliki backgorund ilmu komputer, informasi dan perpustakaan.

Setelah semua data yang diinginkan diperoleh, langkah berikutnya adalah melakukan analisis mendalam pada data-data penting tersebut. Pada proses analisis dilakukan beberapa tahapan. Tahapan-tahapan tersebut adalah koding, menentukan konsep yang tepat, merujuk pada konsep data, mengkategorikan, merujuk pada kategori dengan berbasis data, membuat dan 
menentukan hipotesis, merujuk hipotesis dengan data, mengembangkan teori atau bahkan bisa saja ditemukan teori. Setelah semua tahapan itu dilakukan, maka hasil penelitian sudah dapat diperoleh (Sidiq, 2018).

\section{B. HASIL DAN PEMBAHASAN}

\section{Upaya Pengembangan Website UIN Syarif Hidayatullah Jakarta}

Konten web adalah jenis informasi yang berupa berita, artikel, gambar, atau jenis informasi lainnya yang disimpan di dalam laman sebuah website. Website yang baik adalah website yang memiliki jumlah konten yang banyak dan bermutu (Weideman, 2009). Dalam sudut pandang SEO, konten yang baik adalah konten yang menarik banyak orang untuk membuka dan membacanya. Selain itu kontennya dapat terbaca atau terjangkau (crawled) oleh mesin pencari (Adil, 2016; Ferdiansah, 2020).

UIN Jakarta memiliki satu divisi khusus untuk menangani pengembangan konten web, yaitu Publikasi dan Dokumentasi (Pubdok). Fungsi utamanya adalah meliputi semua kegiatan di lingkungan UIN Jakarta dan memuat beritanya dalam website dan TV lokal milik UIN Jakarta. Pada awal tahun 2019 Divisi Pubdok telah bekerjasama dengan seluruh pengelola website fakultas dan unit pelaksana. Kegiatan ini dilakukan secara serentak di mana setiap admin setiap fakultas dan unit meliput semua kegiatan yang dilaksanakan di unit masing-masing. Hal sama juga pernah dilakukan pada pertengahan 2018 sampai dengan akhir 2019, Lembaga Penjaminan Mutu (LPM) pernah membentuk sebuah tim khusus yang menangani upaya peningkatan rangking webometrics dengan langkah kerja yang hampir sama.

Upaya pengembangan konten website ini telah menunjukan hasil yang cukup signifikan, jumlah halaman web yang awalnya hanya sekitar 400.000an page yang terdeteksi oleh Google menjadi 1.158.680. Namun, apabila dibandingkan dengan 5 website PTKIN yang lain, ada beberapa UIN yang memiliki crawled page yang lebih tinggi lagi. Data lengkapnya dapat dilihat dalam data Ahrefs di bawah ini.

Tabel 2 : Jumlah webpage uinjkt.ac.id

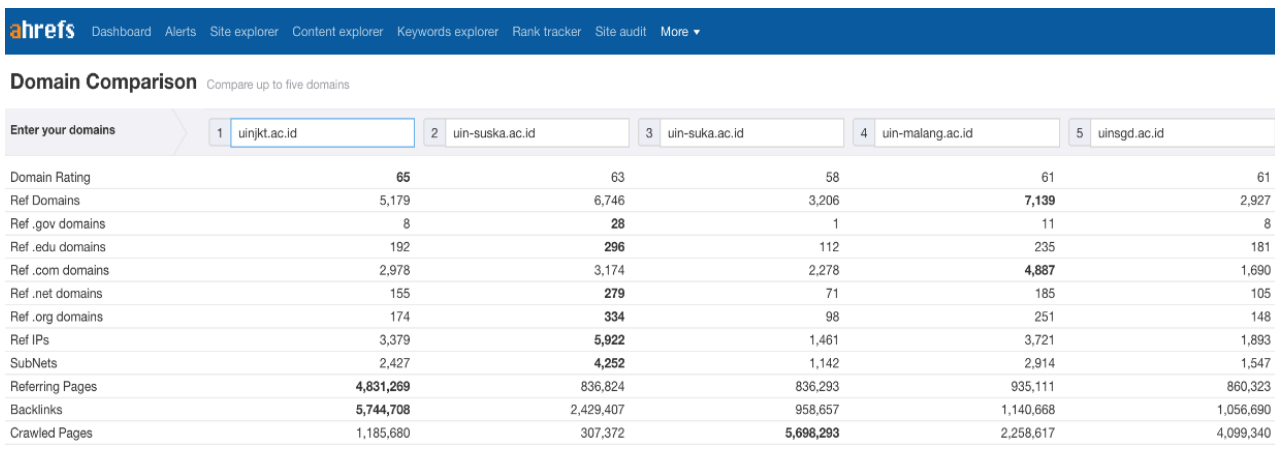


Dalam hal ini kita perlu membedakan antara page dan konten. Page adalah halaman yang memuat berbagai konten. Sedangkan konten itu sendiri adalah sumber-sumber informasi yang terdapat dalam sebuah page website (Basuki, 2014). Dalam perangkingan webometrics, konten ini berperan dalam memenuhi salah satu kriteria perangkingan yaitu presence yang memberikan skor 5\% dari total perangkingan webometrics. Presence adalah kriteria penilaian webometrics yang menunjukan berapa banyak page yang terindeks oleh google. Page itu sendiri dalam sebuah website merupakan alat utama untuk memancing link-link yang dari luar (backlink). Page yang baik akan memuat konten informasi yang baik dan disukai para pengguna internet (Bilro et al., 2018; Muljono, 2019).

Page uinjkt.ac.id telah melewati angka satu juta. Dalam bagian ini akan dideskripsikan page apa saja yang paling banyak menjadi objek pencarian warganet (netizen) dalam website uinjkt.ac.id. Top page uinjkt.ac.id dalam data yang ditampilkan Ahrefs adalah sebagai berikut:

Tabel 3 : Top Page uinjkt.ac.id

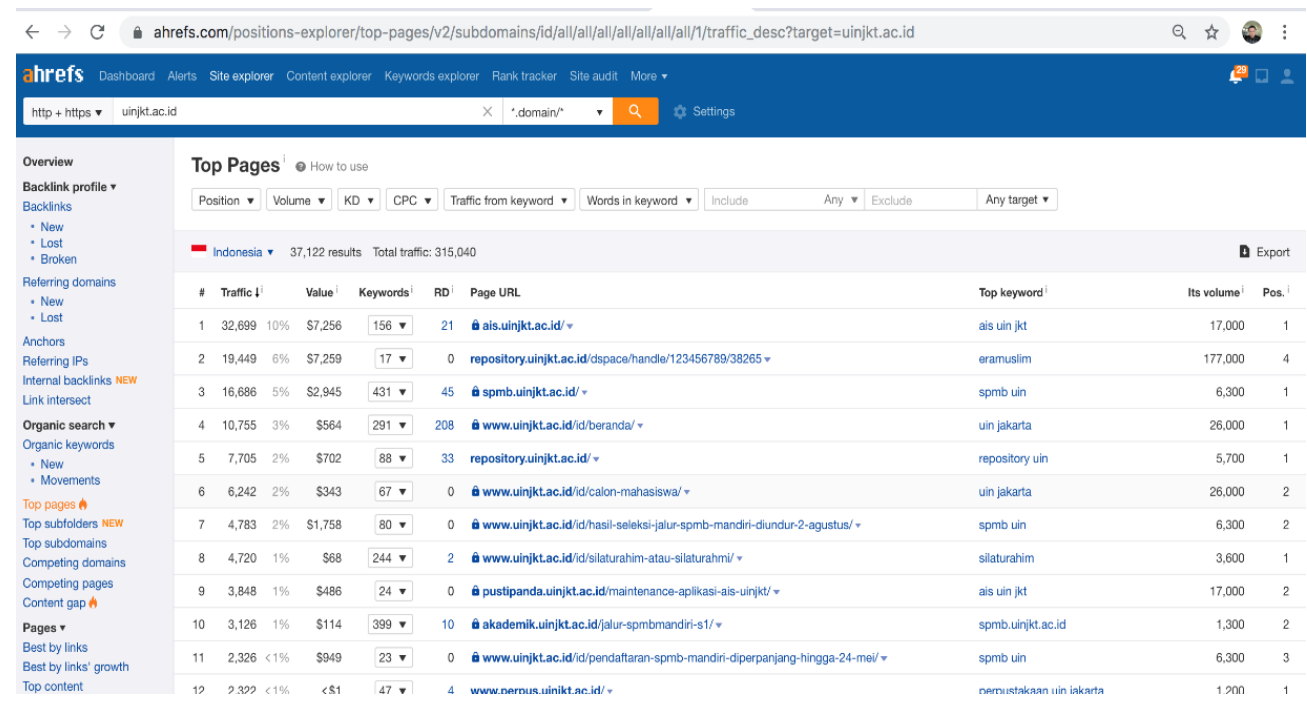

Dalam gambar di atas diketahui bahwa terdapat cukup banyak page yang menjadi objek pencarian utama warganet. Proses penemuan page tersebut dimulai saat pencari informasi memasukan kata kunci di google, setelah itu Google akan menampilkan page-page di uinjkt.ac.id yang memiliki kata kunci yang dimaksud. 


\section{Upaya Indeksasi Konten oleh Google}

Ada beberapa langkah penting agar website beserta seluruh konten yang ada di dalamnya dapat terindeks oleh google (Ziakis et al., 2019). Page uinjkt.ac.id yang terindeks oleh google sudah mencapai 1.185.680.

Hal ini tidak terlepas dari upaya Pustipanda yang telah mendaftarkan website uinjkt di https://www.google.com/webmasters/, begitu juga pustipanda telah mendaftar sitemap websitenya di https://www.google.com/webmasters/tools/sitemap-list.

Langkah yang dilakukan Pustipanda tersebut berdasarkan langkah SEO sudah sangat tepat. Ada beberapa tahapan penting agar sebuah website dapat terindeks oleh google. Pertama buat akun di Google Webmaster dan pastikan bahwa website yang kita kelola sudah terkoneksi dengan akun tersebut di menu Search Console. Caranya adalah dengan mengklik https://www.google.com/webmasters/.

Langkah kedua, kirimkan sitemap ke Google Search Console. Caranya dengan mengklik https://www.google.com/webmasters/tools/sitemap-list. Setelah itu, klik tombol tambahkan atau uji peta situs (Adi, 2017; Kelsey, 2017).

Langkah ketiga adalah dengan melakukan key word research atau penelitian kata kunci dan pesaing. Salah satunya bisa dengan cara tidak berbayar yaitu dengan menginstall fasilitas add on yang diberi nama dengan sebutan SEOquake (Khan \& Mahmood, 2018).

SEOQuake ini dapat didownload di https://www.seoquake.com/index.html. Setelah fasilitas add on tersebut berhasil diinstal dan aktif, langkah selanjuttnya adalah dengan mengetikkan kata kunci yang kita inginkan di Google, kemudian amati website yang berada pada ranking 1-10 di page pertama. Kemudian, kita harus memperhatikan berapa jumlah website yang memiliki Alexa Rank lebih dari 1 juta. Bila kita sudah mendapatkan angkanya, perhatikan pula berapa jumlah hasil pencariannya. Kriterianya adalah kalau website di peringkat 1-10 yang Alexa Rank nya lebih dari 1 juta jumlahnya minimal 3 dan jumah hasil pencariannya kurang dari 500 ribu maka artikel di website kita bisa dengan cepat terindex Google (Husnan \& Java Creativity, 2017).

Langkah berikutnya adalah dengan memastikan bahwa artikel website kita itu minimal mempunyai jumlah kata sebanyak 300 kata. bila belum mencapai 300 kata, kita terpaksa harus mengedit kembali lagi artikel website tersebut dan tambahkan kata-kata sampai lebih dari 300 kata. 
semakin banyak jumlah kata dalam artikel, maka makin cepat artikel website dapat terindex. Langkah yang kelima adalah dengan memastikan bahwa Skor SEO website kita lebih dari 80. Agar kita dapat mengetahui skor SEO dari sebuah website, kita bisa memasukan url website kita ke website https://neilpatel.com/seo-analyzer/. Neilpatel akan memberikan skor website kita dan memberikan penjelasannya lebih detail (Król \& Zdonek, 2020).

Pustipanda sebagai pengembang website di UIN Jakarta telah mendaftarkan website di Google Web Master pada alamat https://www.google.com/webmasters/ dan sitemap websitenya di https://www.google.com/webmasters/tools/sitemap-list. Langkah ketiga yaitu melakukan riset terhadap kata kunci juga dapat dengan mudah dilakukan oleh Pustipanda karena UIN Jakarta sampai dengan Desember 2019 telah melanggan satu website yang bernama ahrefs.com.

\section{Upaya Mendapatkan Backlink}

Apakah ada perbedaan utama antara backlink dengan referring domain ? Ketika satu website melakukan link pada suatu web lain, misalnya dengan mengutip atau menyimpan link dari web tersebut, maka terjadilah referring domain (Visconti, 2020). Bila website tersebut berkali-kali melakukan link pada suatu web tertentu maka itu kemudian disebut dengan backlink. Sehingga dengan ketentuan ini kita bisa memahami bahwa referring domain tidak akan pernah bisa melewati backlink (Astono, 2017).

Berdasarkan bantuan dari tool SEO, ahrefs.com, backlink uinjkt.ac.id dapat dilihat dalam gambar di bawah ini.

Tabel 4 : Backlink dan referring domain

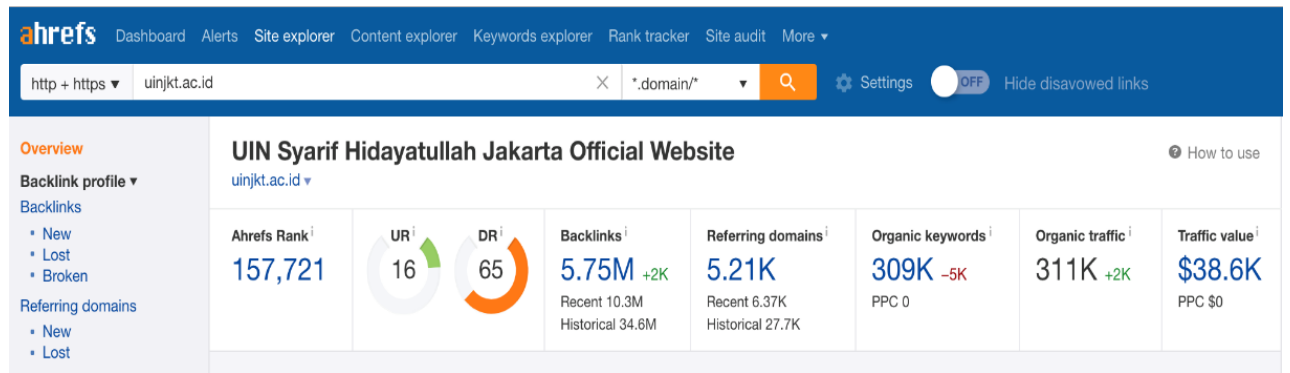

Dari gambar di atas diketahui bahwa jumlah backlink terhadap website uinjkt.ac.id telah mencapai 5.725.141. Dalam pembahasan ini backlink dibedakan menjadi 3 bagian, new backlink, lost backlink, dan broken link.

a. New Backlink 
Pada bagian ini akan dibahas berapa banyak backlink baru yang diterima oleh website uinjkt.ac.id.

Tabel 5 : New backlink uinjkt.ac.id

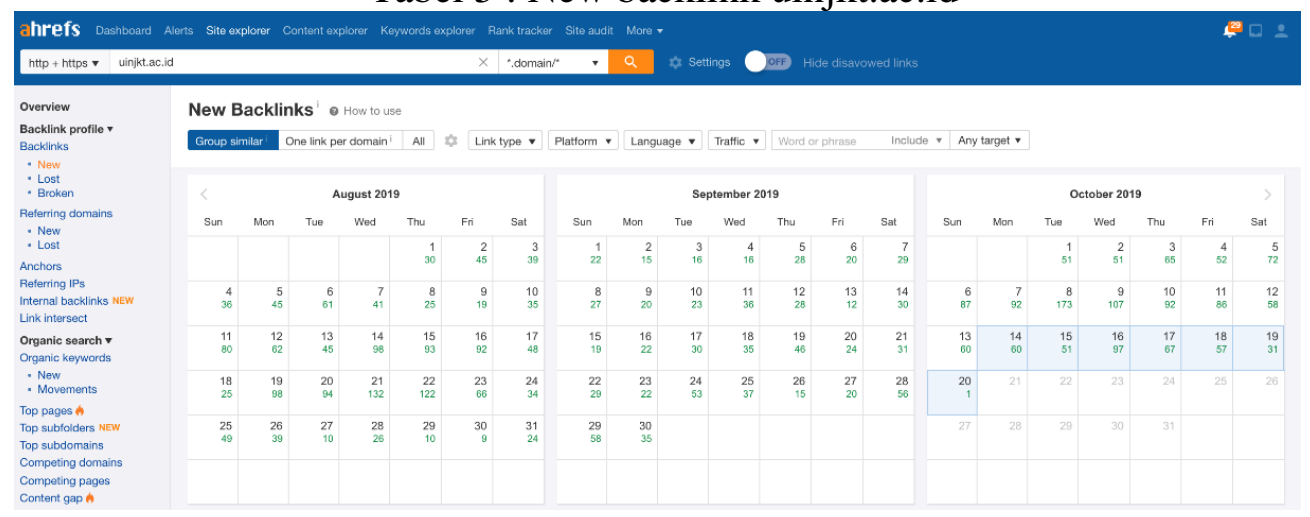

Berdasarkan data pada gambar di atas, pada kisaran AgustusSeptember 2019, backlink yang diterima uinjkt.ac.id berada kisaran 12 - 132 backlink, dengan jumlah total 2486 backlink selama 2 bulan. Apabila dirataratakan maka setiap harinya website uinjkt.ac.id mendapat backlink sebanyak kurang lebih 40 backlink.

Namun sayangnya dari sekian banyak backlink yang diterima oleh uinjkt.ac.id masih terdapat sekian banyak link dari website yang kurang populer dan kurang relevan dengan konten uinjkt.ac.id yang berfokus pada pendidikan dan keagamaan. Banyak backlink yang masuk ke uinjkt.ac.id, melalui spam pada beberapa subdomain uinjkt.ac.id yang terabaikan oleh pengembang pertamanya.

b. Lost Backlink

Lost backlink terjadi ketika salah satu webpage yang bertautan di antara 2 domain yang berbeda mengalami kerusakan atau dihapus (OrduñaMalea, 2021). Hal yang sama juga terjadi pada website uinjkt.ac.id. Dalam data yang diambil dari Ahrefs dapat dilihat keterangan sebagai berikut: 
Tabel 6 : Lost backlink uinjkt.ac.id

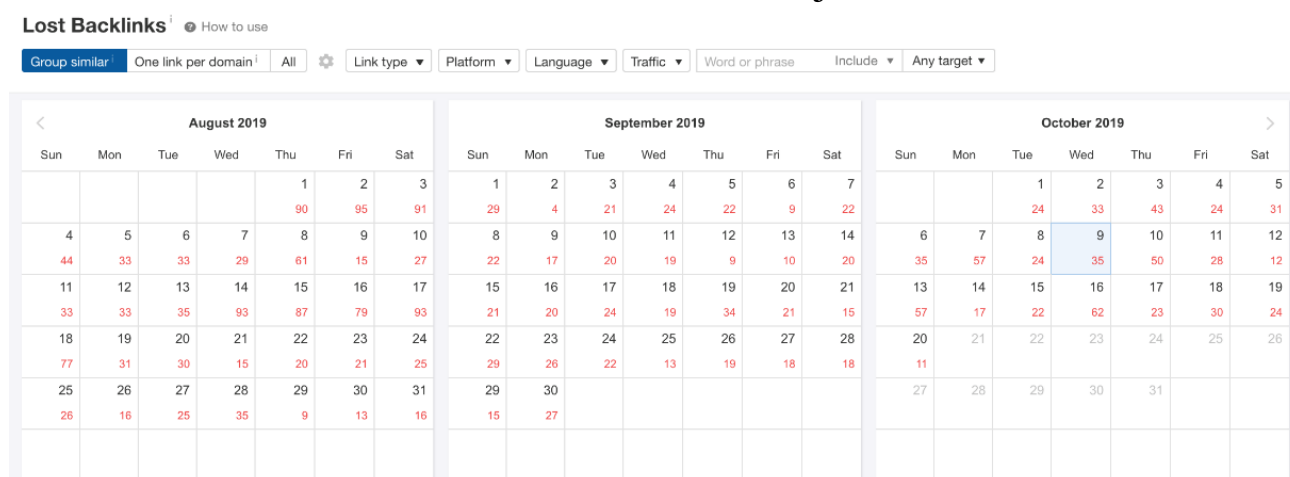

Berdasarkan data pada gambar di atas, diketahui bahwa pada kisaran Agustus-September 2019, lost backlink yang dialami uinjkt.ac.id berada pada kisaran 4 - 95 backlink, dengan jumlah total 1919 lost backlink selama 2 bulan. Apabila dirata-ratakan maka setiap harinya website uinjkt.ac.id kehilangan backlink sebanyak kurang lebih 31 backlink.

c. Broken link

Broken link adalah keadaan di mana sebuah webpage terhapus, rusak atau hilang, sehingga webpage lain yang menggantukan link kepada webpage pertama tidak dapat lagi melacak atau membuat tautan (Múgica, 2020). Dalam data ahrefs, diketahui bahwa broken link uinjkt.ac.id mencapai 7,077 backlink. Hal ini terjadi karena webpage tempat sebuah link masuk hilang atau rusak.

\section{Upaya Mendapatkan Referring Domain}

Seperti telah disampaikan sebelumnya bahwa referring domain adalah domain yang melakukan link pada domain lain. Ketika domain itu melakukan link berkali-kali maka link tersebut disebut sebagai backlink (Shukla, 2017). Sebagai contoh misalnya sebuah website (domain) melakukan link sebanyak 7 kali pada sebuah website A, maka tool SEO akan menyebutkan bahwa website A telah memiliki 1 referring domain, dan 7 backlink.

Untuk mengetahui berapa jumlah referring domain yang dimiliki uinjkt.ac.id, kita dapat melihat gambar di bawah ini: 
Tabel 7 : Referring Domain uinjkt.ac.id

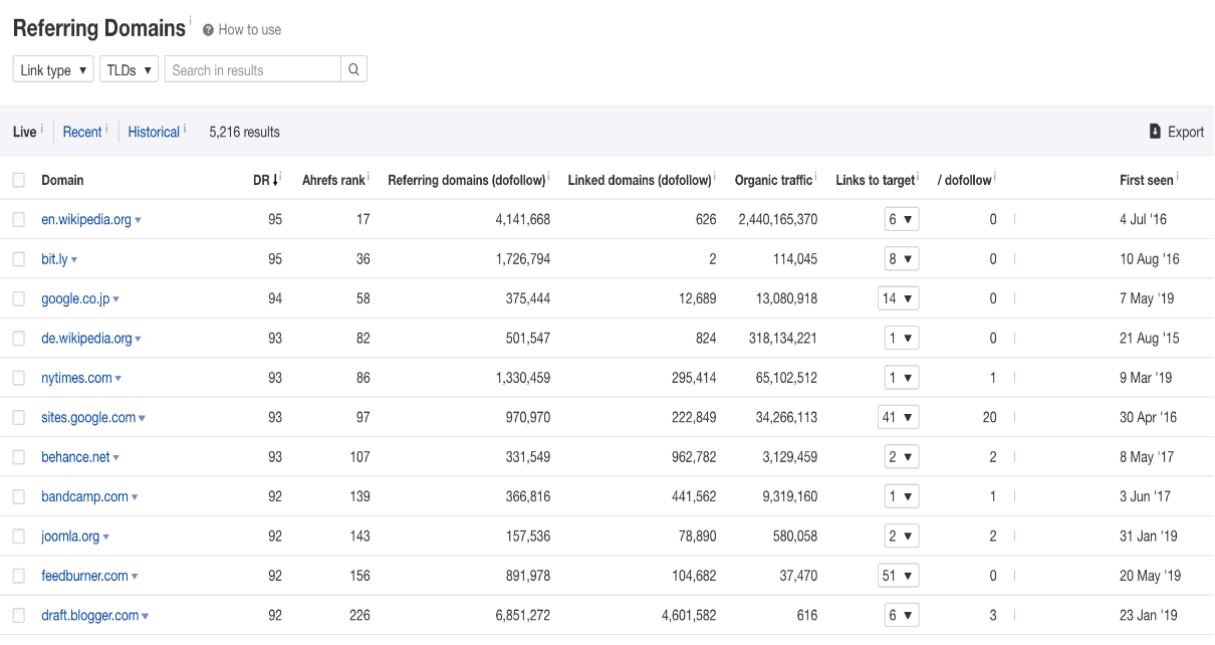

Berdasarkan informasi pada gambar di atas diketahui bahwa jumlah domain yang merefer (referring domain) ke uinjkt.ac.id berjumlah 5,216. Daftar domain yang merefer diurutkan oleh ahrefs.com berdasarkan DR (Domain Rating) tertinggi. Menempati list teratas adalah wikipedia dengan DR 95, diikuti oleh bit.ly dengan DR 95, google.co.jp dengan DR 94, de.wikipedia.org dengan DR 93, nytimes.com dengan DR 93, dan site.google.com dengan DR 93. Masih ada ribuan domain lagi yang merefer ke uinjkt.ac.id.

\section{d. New Referring Domain}

Selanjutnya perlu juga dibahas berapa rata-rata referring domain uinjkt.ac.id yang diperoleh setiap harinya. Berdasarkan data ahref.com, diketahui bahwa pada kisaran Juni-Juli 2019, new referring domain yang dimiliki uinjkt.ac.id berada pada kisaran 1 - 15 referring domain, dengan jumlah total 348 referring domain selama 2 bulan. Apabila dirata-ratakan maka setiap harinya website uinjkt.ac.id mendapatkan referring domain sebanyak kurang lebih 6 referring domain.

\section{e. Lost Referring Domain}

Selain new referring domain kita juga perlu mengetahui domain yang tidak lagi merefer ke uinjkt.ac.id. Untuk mengetahuinya kita dapat melihat gambar di bawah ini: 
Tabel 8 : Referring Domain uinjkt.ac.id

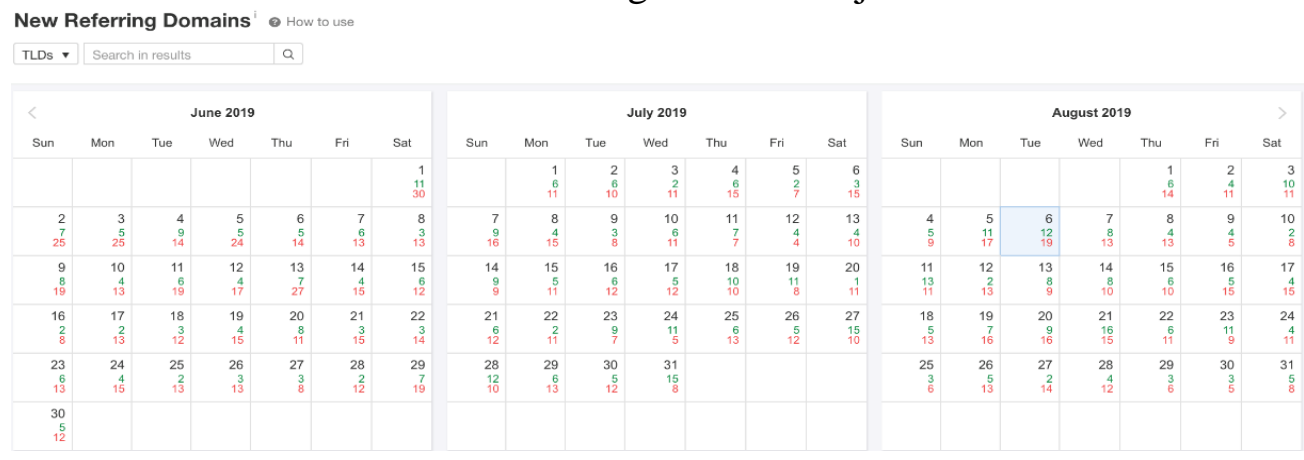

Berdasarkan data pada gambar di atas, diketahui bahwa pada kisaran Agustus-September 2019, lost referring domain pada uinjkt.ac.id berada pada kisaran 4 - 19 referring domain, dengan jumlah total 640 lost referring domain selama 2 bulan. Apabila dirata-ratakan maka setiap harinya website uinjkt.ac.id kehilangan referring domain sebanyak kurang lebih 10 lost referring domain.

Hal ini tentu harus menjadi perhatian serius mengingat jumlah lost referring domain lebih tinggi daripada new referring domain. Namun, tetap juga harus diperhatikan apakah website yang merefer dan kemudian hilang itu website dengan DR tinggi atau hanya website biasa saja.

\section{Upaya Menghadapi Kendala Penghambat Visibilitas}

Dari rangkaian hasil temuan penelitian, ada beberapa kendala yang menjadi penghambat visibilitas website uinjkt.ac.id, apabila dikaitkan dengan perangkingan yang dilakukan oleh Google maupun oleh Webometrics. Beberapa kendala tersebut dapat dikelompokan 3 kendala utama, yaitu kendala dalam pengembangan dan indeksasi konten oleh Google, kendala dengan backlink, dan kendala dengan referring domain.

Dalam kenyataannya memang masih ada unit yang belum begitu aktif untuk mengupdate berita dan artikel dalam subdomain uinjkt.ac.id yang dikelolanya. Hal ini dapat saja karena kesibukan atau karena terbatasnya jumlah personel di unit bersangkutan. Untuk mengantisipasi hal tersebut di atas, Universitas sudah mengeluarkan SK tentang tim pengembangan konten web dengan diberikan sedikit tambahan honorarium yang diberikan setiap 2 bulan sekali.

Dari hasil temuan penelitian diketahui bahwa masih terdapat banyak bad backlink. Bad backlink itu sendiri dapat diakibatkan karena masih terdapat webpage atau subdomain yang tidak terawat. Webpage yang tidak terawat akan mengakibatkan masuknya spam, malware atau bahkan virus. 
Untuk mengantisipasi hal tersebut, sepertinya sangat diperlukan sekali prosedur yang jelas (SOP) pada saat adanya permintaan untuk membuat atau meminta izin hosting pada server UIN Jakarta. SOP ini harus menceritakan dengan jelas tahapan izin pembuatan subdomain, termasuk siapa penangungjawabnya, dan sanksi apa yang akan diterima oleh pemohon apabila subdomainnya tidak dirawat dan tidak diupdate.

Berdasarkan data yang diperoleh ternyata jumlah referring domain yang hilang lebih banyak daripada jumlah referring domain yang diperoleh. Oleh karena itu sangat penting sekali untuk membuat konten yang menarik, memenuhi kaidah jurnalistik, memenuhi kaidah SEO dan merawat konten dari berbagai hal yang merusak seperti spam, malware dan program-program sejenisnya.

Upaya Pustipanda untuk membuat konsep multisite yang menyatukan beberapa subdomain uinjkt.ac.id dalam satu template yang sama, merupakan sebuah langkah yang baik. Multisite memungkinkan pemegang utama sistem (super admin) untuk melakukan antisipasi-antisipasi terhadap kemungkinan masuknya spam atau malware, sehingga tidak terjadi lagi subdomain-subdomain yang disusupi oleh spam atau malware. Konsep multisite juga memungkinkan super admin untuk mengupdate template secara keseluruhan, tidak secara parsial yang membutuhkan proses dan waktu yang cukup panjang.

\section{KESIMPULAN}

Upaya pengembangan konten web uinjkt.ac.id telah dilakukan oleh para pengembang konten web yang dilakukan oleh admin baik yang berada di tingkat pusat maupun di tingkat fakultas dan unit, dengan adanya Surat Keputusan Rektor Tentang Tim Pengembangan Konten. Dalam melaksanakan tugasnya mengembangkan konten web, para admin senantiasa berkomunikasi efektif alam bentuk grup whatsapp untuk saling mengingatkan setiap anggota agar selalu mengupdate subdomain website masing-masing.

Dalam beberapa kasus, masih ditemukan pula page dan subdomain yang tidak terawat dengan baik. Page dan subdomain yang tidak terawat sangat potensial untuk diserang oleh spam, malware dan program sejenis, sehingga menimbulkan banyak bad backlink. Kolom komentar yang dibiarkan terbuka tanpa ada fasilitas approval juga sangat rentan untuk diserang.

Masih banyak ditemukan juga page atau subdomain yang hilang, hal ini akan mengakibatkan terputusnya (broken) link dari website-website yang 
mengutip (Referring domain) domain uinjkt.ac.id. Padahal di antaranya terdapat domain-domain yang kredibel dengan domain rating yang tinggi.

Konsep multisite yang digulirkan oleh Pustipanda adalah sebuah langkah yang baik, karena akan memudahkan kontrol dan meningkatkan keamanan website uinjkt.ac.id. Dengan konsep ini, jumlah subdomain yang menjadi sumber datangnya spam dan malware akan berkurang.

Dengan memperhatikan secara seksama berbagai masalah yang ditemukan pada penelitian ini, maka dapat ditarik kesimpulan besar bahwa semakin banyak dan semakin baik konten web, maka semakin besar peluang untuk mendapat backlink dan referring domain.

Setelah memperhatikan beberapa kesimpulan di atas maka sangat penting sekali untuk menyampaikan saran-saran berikut, komunikasi yang efektif antar pengembang konten web dan pengembang web harus selalu intensif dilakukan. Melihat masih banyaknya konten web yang belum memenuhi kaidah SEO maka sangat perlu dilakukan pelatihan tata cara membuat konten yang baik agar lebih banyak lagi konten web uinjkt.ac.id yang terindeks oleh Google dan mesin pencari lainnya. Mengingat masih ditemukannya subdomain yang tidak aktif dan kurang terawat, maka penting sekali bagi pemangku kebijakan untuk membuat SOP tata cara pembuatan dan pemeliharaan web sehingga seluruh subdomain uinjkt.ac.id bisa berjalan dengan maksimal.

\section{DAFTAR RUJUKAN}

Adi, A. P. (2017). SEO untuk Blog. Elex Media Komputindo.

Adil, M. (2016). Panduan Praktis Digital Marketing untuk Pebisnis. Sadarhati Book Expert.

Aguillo, I. F. (2015a). About Us | Ranking Web of Universities: Webometrics ranks 30000 institutions. Ranking Web of Universities. http://webometrics.info/en/About_Us

Aguillo, I. F. (2015b). Methodology | Ranking Web of Universities: Webometrics ranks 30000 institutions. Ranking Web of Universities. http://webometrics.info/en/Methodology

Astono, R. (2017). The Book of SEO. Gaptex Indo Media.

Basuki, A. P. (2014). Proyek Membangun Website Berbasis PHP dengan Codeigniter

(Yogyakarta).

Lokomedia. 
//opac.fah.uinjkt.ac.id/index.php?p=show_detail\&id=9633\&keywords =rekayasa+web

Bilro, R. G., Loureiro, S. M. C., \& Ali, F. (2018). The role of website stimuli of experience on engagement and brand advocacy. Journal of Hospitality and Tourism Technology, 9(2), 204-222. https://doi.org/10.1108/JHTT-12-2017-0136

Ferdiansah, R. (2020). Belajar Menjadi Blogger Hingga Menghasilkan Jutaan. Setiawan Publisher.

Fraenkel, J. R., \& Wallen, N. E. (2014). How To Design and Evaluate Research in Education. McGraw-Hill Education.

Hollander, J. A. (2004). The Social Contexts of Focus Groups. Journal of Contemporary Ethnography, 33(5), 602-637. https://doi.org/10.1177/0891241604266988

Husnan, F. \& Java Creativity. (2017). Membangun Website Interaktif dengan Blogger. Elex Media Komputindo.

Kelsey, T. (2017). Explore Indexing and Webmaster Tools/Search Console. In T. Kelsey (Ed.), Introduction to Search Engine Optimization: A Guide for Absolute Beginners (pp. 97-109). Apress. https://doi.org/10.1007/978-1-4842-2851-7_7

Khan, M. N. A., \& Mahmood, A. (2018). A distinctive approach to obtain higher page rank through search engine optimization. Sādhanā, 43(3), 43. https://doi.org/10.1007/s12046-018-0812-3

Król, K., \& Zdonek, D. (2020). Aggregated Indices in Website Quality Assessment. Future Internet, 12(4), 72. https://doi.org/10.3390/fi12040072

Maryam, S., Azam, S., Samad, S., \& Sara, J. (2010). Investigating Web Impact Factors Of Type 1, Type 2 And Type 3 Medical Universities In Iran. $\quad 1(3)$, 34-41. https://www.sid.ir/en/Journal/ViewPaper.aspx?ID=180839

Múgica, I. O. (2020). Technical identifiers of fraudulent web pages, a systematic literature review. http://urn.kb.se/resolve?urn=urn:nbn:se:his:diva-19048

Muljono, R. K. (2019). Digital Marketing Concept: Penggunaan Konsep Dasar Digital Marketing untuk Membuat Perubahan Besar. Gramedia Pustaka Utama. 
Muntashir. (2012). Analisis Webometrics Pada Perpustakaan Perguruan Tinggi Negeri di Indonesia. Visi Pustaka, 14(2), 39-49.

Orduña-Malea, E. (2021). Dot-science top level domain: Academic websites or dumpsites? Scientometrics. https://doi.org/10.1007/s11192-02003832-8

Pribadi, W. (2010). 16 Cara Efektif Mendatangkan Pelanggan Lewat Internet. Bukune.

Rahardja, U., Dewi, E. N., \& Lutfiani, N. (2017). Peningkatan Rank Webometrics Menggunakan Metode Inbound Dan Outbound Pada Perguruan Tinggi. SISFOTENIKA, 7(1), 1-12. https://doi.org/10.30700/jst.v7i1.129

Saputra, D. H., Sutiksno, D. U., Kusuma, A. H. P., Romindo, R., Wahyuni, D., Purnomo, A., \& Simarmata, J. (2020). Digital Marketing: Komunikasi Bisnis Menjadi Lebih Mudah. Yayasan Kita Menulis.

Shukla, A. (2017). Do Index Pages Attract Higher Backlinks? : An Analytical Study of Library Websites. Library Philosophy and Practice (eJournal). https://digitalcommons.unl.edu/libphilprac/1531

Sidiq. (2018, May 11). Analisis Data Kualitatif: Penjelasan dan Contohnya. Sosiologis.Com. http://sosiologis.com/analisis-data-kualitatif

Supradono, B. (2010). Strategi Meningkatkan Kinerja Web Universitas Muhammadiyah Semarang Menuju Peringkat Webometrics. Media Elektrika, 3(1), 49-63. https://doi.org/10.26714/me.3.1.2010.\%p

Visconti, R. M. (2020). Domain Name and Website Valuation. In The Valuation of Digital Intangibles: Technology, Marketing and Internet (pp. 295-325). Springer International Publishing. https://doi.org/10.1007/978-3-030-36918-7_11

Weideman, M. (2009). Website Visibility: The Theory and Practice of Improving Rankings. Elsevier Science.

Ziakis, C., Vlachopoulou, M., Kyrkoudis, T., \& Karagkiozidou, M. (2019). Important Factors for Improving Google Search Rank. Future Internet, 11(2), 32. https://doi.org/10.3390/fi11020032 